\title{
Identification and characterization of intervening sequences within 23S rRNA genes from more than 200 Campylobacter isolates from seven species including atypical campylobacters
}

\author{
Akihiro Tazumi ${ }^{1}$, Yuki Kakinuma ${ }^{1}$, Naoaki Misawa ${ }^{2}$, John E Moore*3, \\ Beverley C Millar ${ }^{4}$ and Motoo Matsuda ${ }^{1}$
}

\begin{abstract}
Address: ${ }^{1}$ Laboratory of Molecular Biology, School of Environmental Health Sciences, Azabu University, Sagamihara 229-8501, Japan, ${ }^{2}$ Department of Veterinary Public Health, Faculty of Agriculture, University of Miyazaki, Miyazaki 889-2192, Japan, ${ }^{3}$ School of Biomedical Sciences, University of Ulster, Cromore Road, Coleraine, Co Londonderry, BT52 1SA, Northern Ireland, UK and ${ }^{4}$ Department of Bacteriology, Northern Ireland Public Health Laboratory, Belfast City Hospital, Belfast, BT9 7AD, Northern Ireland, UK

Email: Akihiro Tazumi - de0702@azabu-u.ac.jp; Yuki Kakinuma - molbio0704@yahoo.co.jp; Naoaki Misawa - a0d90lu@cc.miyazaki-u.ac.jp; John E Moore* - j.moore1@ulster.ac.uk; Beverley C Millar - bcmillar@niphl.dnet.co.uk; Motoo Matsuda - matsuda@azabu-u.ac.jp

* Corresponding author
\end{abstract}

Published: II December 2009

Received: 9 June 2009

BMC Microbiology 2009, 9:256 doi:10.1 I86/147I-2180-9-256

Accepted: II December 2009

This article is available from: http://www.biomedcentral.com/I47I-2/80/9/256

(C) 2009 Tazumi et al; licensee BioMed Central Ltd.

This is an Open Access article distributed under the terms of the Creative Commons Attribution License (http://creativecommons.org/licenses/by/2.0), which permits unrestricted use, distribution, and reproduction in any medium, provided the original work is properly cited.

\begin{abstract}
Background: Identification and characterization of intervening sequences (IVSs) within $23 \mathrm{~S}$ rRNA genes from Campylobacter organisms including atypical campylobacters were carried out using two PCR primer pairs, designed to generate helix 25 and 45 regions.

Results: Only C. sputorum biovar sputorum LMG7975 and fecalis LMG853I, LMG8534 and LMG6728 of a total of 204 Campylobacter isolates $(\mathrm{n}=56$ C. jejuni; $\mathrm{n}=$ II C. coli; $\mathrm{n}=33$ C. fetus; $\mathrm{n}$ $=43 \mathrm{C}$. upsaliensis; $\mathrm{n}=30 \mathrm{C}$. hyointestinalis; $\mathrm{n}=4 \mathrm{C}$. sputorum biovar sputorum; $\mathrm{n}=5 \mathrm{C}$. sputorum biovar fecalis; $n=5$ C. sputorum biovar paraureolyticus; $n=10$ C. concisus; $n=7$ C. curvus) were shown to carry IVSs in helix 25 region. C. sputorum biovar fecalis LMG853I and LMG8534, interestingly, carried two different kinds of the $23 \mathrm{~S}$ rRNA genes with and without the IVS, respectively. Consequently, in a total of 265 isolates of 269 , including $65 \mathrm{C}$. lari isolates examined previously, the absence of IVSs was identified in the helix 25 region. In the helix 45 region, all the C. hyointestinalis, $C$. sputorum and $C$. concisus isolates were shown not to carry any IVSs. However, the 30 of 56 C. jejuni isolates (54\%), 5 of I I C. coli (45\%), 25 of 33 C. fetus (76\%), 30 of 43 C. upsaliensis $(70 \%)$ and 6 of 7 C. curvus (90\%) were shown to carry IVSs. In C. jejuni and C. upsaliensis isolates, two different kinds of the $23 \mathrm{~S}$ rRNA genes were also identified to occur with and without IVSs in the helix 45 region, respectively.
\end{abstract}

Conclusions: Secondary structure models were also constructed with all the IVSs identified in the present study. In the purified RNA fractions from the isolates which carried the I6S or 23S rRNA genes with the IVSs, no I6S or 23 S rRNA was evident, respectively.

\section{Background}

Thermophilic Campylobacter species, primarily Campylobacter jejuni and C. coli are the most frequently recognized cause of acute bacterial gastroenteritis in humans in the Western world. In relation to human campylobacteriosis,
C. upsaliensis, C. hyointestinalis, C. lari, C. fetus and C. sputorum biovar sputorum have also been demonstrated to be implicated as gastrointestinal pathogens though these are rare $[1,2]$. These Campylobacter organisms have also been isolated from animals. 
Moreover, C. concisus, C. curvus and so on are detected in association with the oral cavity [3]. Alternatively, C. sputorum biovar fecalis is isolated from animals [4]. A multiplex PCR assay has recently developed for the identification of C. coli, C. fetus, C. hyointestinalis subsp. hyointestinalis, C. jejuni, C. lari and C. upsaliensis [5]. Thus, at this time, the genus Campylobacter comprises 18 species [6]

As already shown, the genus Campylobacter is, in general, indicated to carry the three copies of rRNA gene operon [7-9]

In relation to bacterial 23S rRNA genes, the occurrence of intervening sequences (IVSs) [10-12] and the fragmentation of 23S rRNA [13-16] have been demonstrated.

In the genus Campylobacter, the $\varepsilon$-subdivision of the Proteobacteria, the occurrence of internal transcribed spacers was first described in helix 45 region within 23S rRNA gene in two of four C. jejuni, in both C. fetus and in one of two C. upsaliensis strains, when a total of 17 Campylobacter strains ( $\mathrm{n}=4$ C. jejuni; $\mathrm{n}=2$ C. coli; $\mathrm{n}=1$ C. lari; $\mathrm{n}=2$ C. upsaliensis; $\mathrm{n}=2$ C. fetus; $\mathrm{n}=1$ C. concisus $\mathrm{n}=1$ C. hyointestinalis; $\mathrm{n}=1$ C. mucosalis; $\mathrm{n}=3$; C. sputorum) were examined [17]. In addition, three of seven $C$. jejuni isolates examined were found to carry fragmented 23S rRNA [18]. Moreover, the occurrence of fragmented 23S rRNA correlated with the presence of an IVS within the 23S rRNA genes. It was described that the presence of transcribed spacers is common in Campylobacter spp. (59\%; $\mathrm{n}=21$ C. jejuni and $\mathrm{n}=$ 11 C. coli) [19]. All Campylobacter isolates containing transcribed spacers in their 23S rRNA gene sequences produced fragmented 23S rRNAs [19]. Most recently, among 104 strains of $C$. coli from turkeys, 69 strains harbored IVSs in all three 23S rRNA genes, whereas the other 35 strains lacked IVSs from at least one of the genes [20].

We have already reported the absence of IVSs shown in both the helix 25 (first quarter) and 45 (central) regions within 23S rRNA genes among a total of 65 isolates of $C$. lari $[\mathrm{n}=38$ urease-positive thermophilic Campylobacter (UPTC) [21] and $\mathrm{n}=27$ urease-negative (UN) C. lari] obtained from different sources and in several countries, by using PCR amplification, TA cloning and sequencing procedures [22]. In addition, the intact 23S rRNA was also identified in the C. lari isolates examined, resulting in no production of the fragmented 23S rRNA [22].

Thus, it would be important to clarify the molecular biological entities of the occurrence and the sequence structures of IVSs within the 23S rRNA genes in the much more isolates of several other species than C. lari of the genus Campylobacter including atypical species.
However, studies on molecular characterization and comparative analysis of IVSs within the 23S rRNA genes and these 23S rRNA fragmentations in much more than 200 Campylobacter isolates of C. jejuni, C. coli, C. fetus, and some other atypical Campylobacter species, namely $C$. upsaliensis, C. hyointestinalis, C. sputorum biovar sputorum, biovar fecalis, biovar paraureolyticus, C. concisus and $C$. curvus have not yet been reported. Therefore, we aimed to clarify molecular characteristics of IVSs within the $23 \mathrm{~S}$ rRNA gene sequences and 23S rRNA fragmentations in these campylobacters other than C. lari, which has already been demonstrated not to harbor any IVSs [22]. In addition, the authors wished to comparatively analyze the IVSs among the Campylobacter organisms.

\section{Results \\ IVSs in the helix $\mathbf{2 5}$ region}

In the present study, two PCR primer pairs, f-/r-Cl23h25, designed to generate the helix 25 (first quarter) and, $\mathrm{f}-\mathrm{r}$ $\mathrm{Cl} 23 \mathrm{~h} 45$, the helix 45 (central) regions within the $23 \mathrm{~S}$ rRNA gene sequences with the 204 Campylobacter isolates were employed.

When PCR was first carried out on the 204 isolates using the primer pair (f-/r-Cl23h25), amplicons were generated. Some of the examples are shown in Fig. 1. Following sequencing and analysis, only the four cases, C. sputorum biovar sputorum LMG7975 and biovar fecalis LMG8531, LMG8534 and LMG6728 isolates, were shown to carry IVSs in the helix 25 region among these isolates of more than 200. The sequence data in the helix 25 region from C. sputorum isolates are aligned in Fig. 2. As shown in Fig. 2 , identical IVS occurred in the helix 25 region within $23 S$ rRNA genes from the four C. sputorum isolates. Regarding the three C. sputorum biovar fecalis isolates, moreover, two different kinds of the 23S rRNA genes were identified to occur with and without the IVS, respectively (Fig. 2).

\section{IVSs in the helix 45 region}

Then, we carried out PCR amplification of the IVSs, in the central region (helix 45 region) within 23S rRNA gene sequences with the 204 Campylobacter isolates, using the primer pair f-/r-Cl23h45. Some examples of the PCR amplicons are shown in Fig. 3. Following sequencing and alignment analyses, in the helix 45 region, $30 \mathrm{C}$. hyointestinalis, fourteen C. sputorum biovar sputorum, biovar fecalis and paraureolyticus and $10 \mathrm{C}$. concisus isolates were shown not to carry any IVSs. In addition, however, regarding the other Campylobacter organisms examined in the present study, 30 of 56 C. jejuni (54\%), 5 of 11 C. coli (45\%), 25 of 33 C. fetus (76\%), 30 of 43 C. upsaliensis $(70 \%)$ and 6 of 7 C. curvus (86\%) isolates were shown to carry the IVSs in the helix 45 region. Some of the sequence data of the IVSs in the helix 45 region were aligned in Fig. 


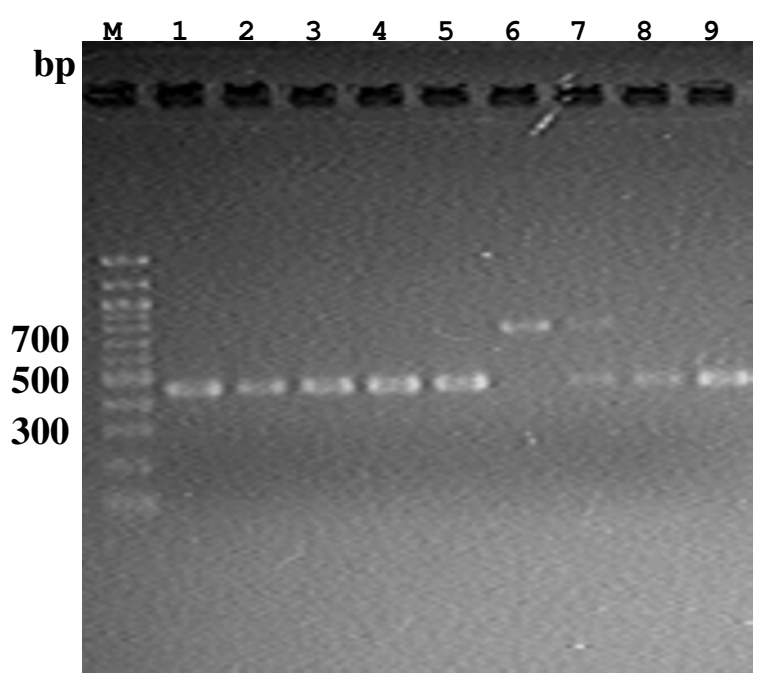

Figure I

Profiles of PCR products amplified with Campylobacter isolates using a primer pair of $\mathrm{f}-/ \mathrm{r}-\mathrm{Cl} 23 \mathrm{~h} 25$. Lane M, 100 bp DNA ladder (New England Biolabs Inc. England, UK); Lane I, C. jejuni 8I-I76; lane 2, C. coli I65; lane 3, C. upsaliensis LMG8850; lane 4, C. fetus ATCC27374; lane 5, C. hyointestinalis ATCC352 17; lane 6, C. sputrum bv. sputorum LMG7975; lane 7, C. sputorum bv. fecalis LMG853I; lane 8, C. concisus LMG7789; lane 9, C. curvus LMG7609.
4. Regarding the IVS sequences in the helix 45 region, four IVSs with similar sequences occurred in the C. jejuni and C. upsaliensis species, respectively, and two also in the C. curvus isolates (Fig. 4 and Table 1). In addition, one kind of IVS with an identical sequence occurred in the C. coli and C. fetus isolates, respectively (Fig. 4), Moreover, the eight IVSs in the C. jejuni and C. upsaliensis isolates showed high sequence similarities to each other ( $90 \%)$, and one kind of IVS in the C. jejuni and C. coli showed an identical sequence (Fig. 4). Four kinds of IVSs in the $C$. upsaliensis isolates, interestingly, carried two characteristic insertion sequences of several base pairs (bp) and twenty and several bp at the two positions (Fig. 4). In C. jejuni (isolates nos. HP5075 and HP5095) and C. upsaliensis (26-4 and 40-1), two different kinds of the 23S rRNA genes were identified to occur with and without the IVS in the helix 45 region. Moreover, multiple and heterogeneous IVSs were shown in C. upsaliensis 48-1 and 68-3 isolates, respectively. Consequently, identification of the IVSs within the 23S rRNA genes from the 207 Campylobacter isolates is summarized in the Table 1.

\section{Secondary structure models of the IVSs}

Regarding the IVSs identified in the present study, within the 23S rRNA gene sequences from the Campylobacter isolates examined, secondary structure models were constructed with all the IVSs shown in Table 1. Fig. 5 and 6

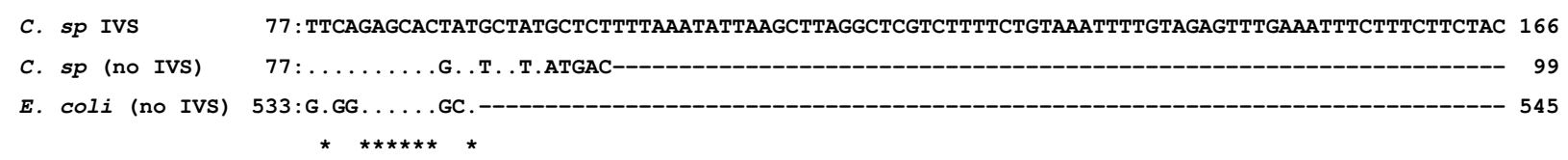

\section{Figure 2}

Sequence alignment analysis in the helix 25 within 23S rRNA gene sequences from Campylobacter isolates. Numbers at the left and right refer to the nucleotide positions determined in the present study. Dots indicate identical bases; changes are explicitly indicated: dashes are deletions; identical positions in all cases are marked by asterisks. Nucleotide sequence data in the helix 25 region within the rrnB operon from the Escherichia coli strain (J0I695), identified to lack IVSs, were also aligned for comparison. C. sp, C. sputorum 
show some examples of the secondary structure models of the IVSs in helix 25 (the first quarter; Fig. 5) and helix 45 (central; Fig. 6) regions. In the present models, stem and loop structures were identified in all IVSs.

\section{Gel electrophoresis of purified RNA}

Denaturing agarose gel electrophoresis profiles of purified RNA from the Campylobacter isolates was carried out to clarify if the primary RNA transcripts of 23S rRNA were fragmented in the isolates or not. Purified RNA from $E$. coli DH5 $\alpha$ cells, identified to lack IVSs, was also employed as a reference marker (lane 1 in Fig. 7). In the purified RNA fraction from the isolates of C. sputorum biovar sputorum LMG7975 (lane 2), whose 23S rRNA gene(s) was demonstrated to carry IVSs in the helix 25, no 23S rRNA was evident in the fraction (Fig. 7A). Instead of the $23 \mathrm{~S}$ rRNA, other smaller RNA fragments were identified (lane 2 in Fig. 7A). Regarding the C. sputorum biovar fecalis LMG8531, two large rRNA bands consisting of an intact and a fragmented 23S rRNAs, were identified to occur in the isolate (lane 3). Some other examples of $23 \mathrm{~S}$ rRNAs whose genes were identified not to carry IVSs in the helix 25 region, are also shown in the Figure. (lanes 4, 5, 6, 8, 9 and 10 in Fig. 7A). Thus, intact 23S rRNAs were identified in Campylobacter isolates containing no IVSs in the helix 25 region. In addition, in Fig. 7B, some of the denaturing agarose gel electrophoresis profiles of purified RNA from the Campylobacter isolates, whose helix 45 regions were examined, are shown. No $23 \mathrm{~S}$ rRNA and fragmented other smaller RNA fragments were evident in the some purified RNA fractions, and intact $23 \mathrm{~S}$ rRNAs were evident in other RNA fractions.

In relation to the $16 \mathrm{~S}$ rRNA molecules from the four isolates of C. sputorum biovar sputorum LMG7975 (lane 2), biovar fecalis LMG8531 (lane 3) and LMG11763 (lane 4 in Fig. 7A) and C. curvus LMG7609 (lane 6 in Fig. 7B), sur-

Table I: IVSs within 235 rRNA genes from Campylobacter organisms analyzed in the present study

\begin{tabular}{llll}
\hline Organism & Isolate & IVS name & Accession No. \\
\hline C. sputorum & LMG7975 & C. sp IVS & $\underline{A B 49 \mid 949}$ \\
C. sputorum & LMG8535 & C. sp no IVS & $\underline{A B 49 \mid 950}$ \\
C. jejuni & $86-375$ & C. je IVSA & $\underline{A B 49 \mid 95 I}$ \\
C. jejuni & $85-3$ & C. je IVSB & $\underline{A B 49 \mid 952}$ \\
C. jejuni & HP5090 & C. je IVSC & $\underline{A B 49 \mid 953}$ \\
C. jejuni & HP5I00 & C. je IVSD & $\underline{A B 49 \mid 954}$ \\
C. coli & 27 & C. co IVS & $\underline{A B 49 \mid 955}$ \\
C. upsaliensis & GII04 & C. up IVSA & $\underline{A B 49 \mid 956}$ \\
C. upsaliensis & $60-I$ & C. up IVSB & $\underline{A B 49 \mid 957}$ \\
C. upsaliensis & 2 & C. up IVSC & $\underline{A B 49 \mid 958}$ \\
C. upsaliensis & I5 & C. up IVSD & $\underline{A B 49 \mid 959}$ \\
C. fetus & cf2-I & C. fe IVS & $\underline{A B 49 \mid 960}$ \\
C. curvus & LMG76I0 & C. cu IVSA & $\underline{A B 49|96|}$ \\
C. curvus & LMGII033 & C. cu IVSB & $\underline{A B 49 \mid 962}$
\end{tabular}

prisingly, slightly shorter RNAs than the $16 \mathrm{~S}$ were identified in these isolates, instead of the 16S rRNA species.

\section{Discussion}

We have already shown no IVSs, in the helix 25 regions within the 23S rRNA genes among a total of 65 isolates of C. lari [ $\mathrm{n}=27$ UN C. lari; $\mathrm{n}=38$ UPTC [22]. Consequently, in 265 isolates of 269 Campylobacter isolates of the nine species $(\mathrm{n}=56$ C. jejuni; $\mathrm{n}=11$ C. coli; $\mathrm{n}=33 \mathrm{C}$. fetus: $\mathrm{n}=65$ C. lari; $\mathrm{n}=43$ C. upsaliensis; $\mathrm{n}=30$ C. hyointestinalis; $\mathrm{n}=14$ C. sputorum; $\mathrm{n}=10$ C. concisus; $\mathrm{n}=7$ C. curvus) examined, the absence of IVSs was identified in helix 25 region within 23S rRNA genes. Moreover, until now, no IVSs have been identified in the helix 25 region within $23 \mathrm{~S}$ rRNA genes, from more than 100 Campylobacter isolates of the 8 species (C. jejuni, C. fetus, C. upsaliensis, C. coli, C. lari, C. concisus, C. hyointestinalis, C. mucosalis) by other research groups [17-20]. Thus, IVS is extremely rare in the helix 25 region within the $23 \mathrm{~S}$ rRNA genes from the Campylobacter organisms. Therefore, this is the first scientifically significant report of IVSs in the helix 25 from C. sputorum biovar sputorum and biovar fecalis among Campylobacter organisms. In addition, no IVSs have been identified to occur in the helix 45 from C. sputorum strains (C. sputorum biovar bubulus, biovar fecalis and biovar sputorum) [17]. Regarding the 23S rRNA, however, fragments smaller than intact 23S rRNA were visible on the gel for C. sputorum biovar bubulus and fecalis strains by using a northern blot hybridization analysis [17].

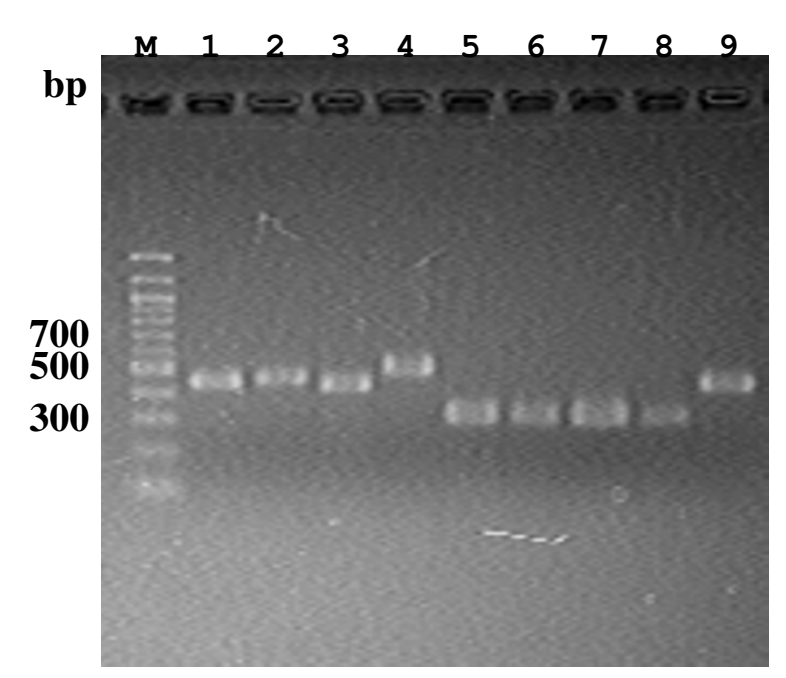

\section{Figure 3}

Electrophoretic profiles of PCR products amplified with Campylobacter isolates using a primer pair of $f-I$ $\mathbf{r}-\mathrm{Cl} 23 \mathrm{~h} 45$. For lane $\mathrm{M}$ and lane I to 9 , see the legend to the Figure I. 
c. je IVSA

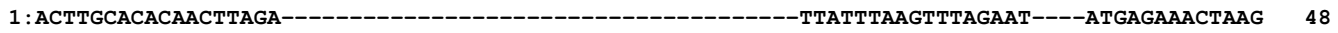

C. je IVSB

c. je IVSC

c. je IVSD

C. co IVS

C. up IVSA

C. up IVSB

c. up IVSC

c. up IVSD

c. fe IVS

C. Cu IVSA

C. Cu IVSB

E. coli (no IVS) $1164: \mathrm{CA}--$. GACGCTT

$1: \ldots \ldots$. . . . . .

$1: \ldots \ldots, \ldots \ldots \ldots \ldots, \ldots \ldots \ldots \ldots \ldots$

$1: \ldots \ldots \ldots \ldots \ldots \ldots \ldots \ldots \ldots$

$1: \ldots \ldots$ G. . . . . . .

$1: \ldots \ldots \ldots \ldots \ldots \ldots$. $\ldots \ldots$. . . . . . . . . . . A 48

$1: \ldots \ldots \ldots \ldots \ldots \ldots \ldots$. . . . . . . . . . . . . . A 48

$1: \ldots \ldots \ldots \ldots \ldots \ldots \ldots$. $\ldots$. . . . . . . . . . . . A 48

$1: \ldots \ldots \ldots \ldots \ldots \ldots$.- $\ldots \ldots$. . . . .-- . . . . . A 48

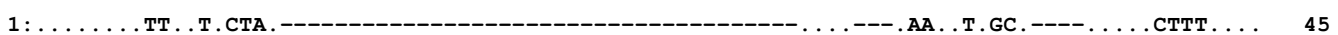

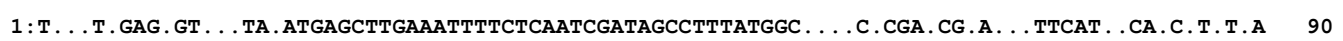

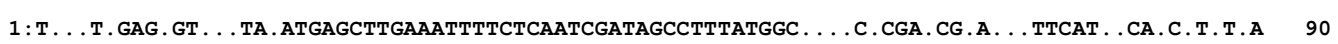

*

C. je IVSA

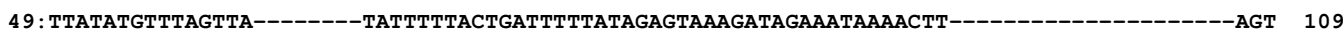

C. je IVSB

c. je IVSC

c. je IVSD

c. co IVS

c. up IVSA

c. up IVSB

c. up IVSC

c. up IVSD

c. fe IVS

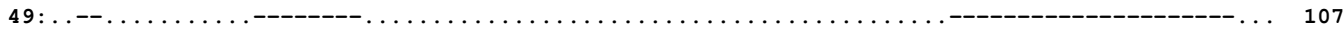

$47:--------\ldots \ldots$

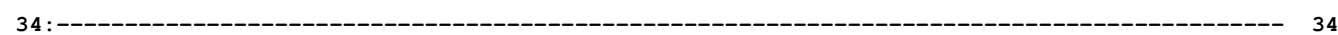

$49: \ldots \ldots \ldots \ldots \ldots \ldots \ldots \ldots \ldots \ldots \ldots \ldots \ldots \ldots \ldots \ldots$

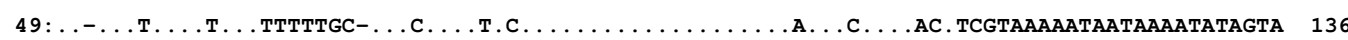

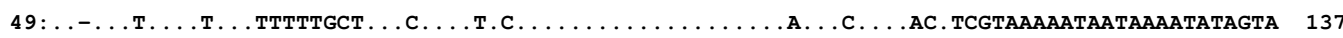

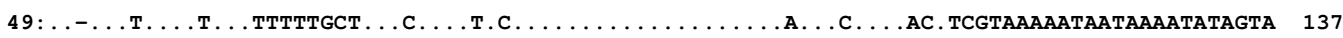

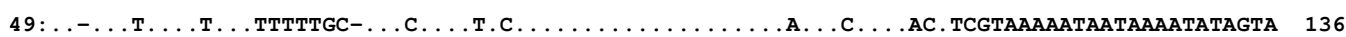

46 : . . . . T.C.CA.-------A. . . AATTGC.C.CA. . . . T. . .

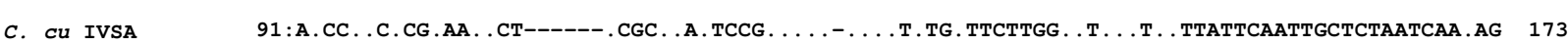

C. cu IVSB $91:$ A.CC..C.CG.AA..CT-----.CGC..A.TCCG...T...T.TG.TTATTGG..T..T.TAA----------AATTTA.AG 163

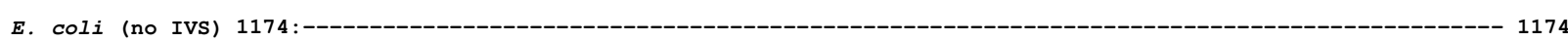

C. je IVSA

110 : AAAATCAGTA---AAAATATTCTTAGACTAA---AGTT--AAGTAGTTTAAGTTGTGTGCAA-GT

165

C. je IVSB

c. je IVSC

c. je IVSD

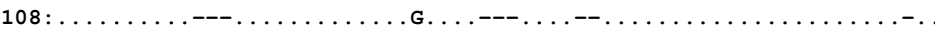

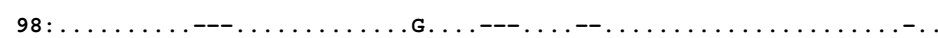

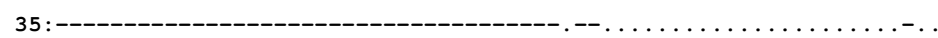

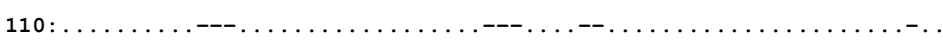

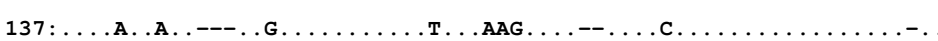

C. up IVSA

C. up IVSB

C. up IVSC

C. up IVSD

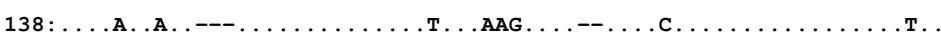

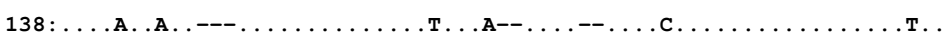

$137: \ldots$. . . A. .------

86:-----TTA.G---.G. .A. . AG. . TAG. . . AAT. A. . AG. . . A. . AG. A. . AA. . . . .

174 : . T. GATTAA. CGT . . . . . GACA. . СT. . . AAAGAG. ATG. A.----- . . CA. AGA. . CT . .

C. cu IVSA

C. $\mathrm{Cu}$ IVSB

164 : . C. GATTAA. CGT . . . . . GACA. . TT. . AAAGAG. ATG. A.-----. . . CA. AGA . CT . .

\section{Figure 4}

Sequence alignment analysis in the helix 45 within 235 rRNA gene sequences from Campylobacter isolates. $C$. je, C. jejuni;C. co, C. coli;C. up, C. upsaliensis;C. fe, C. fetus;C. cu, C. curvus. C. je IVSA, 86-375; B, 85-3; C, HP5090; D, HP5I00; C. co, 27; C. up IVSA, GII04; B, 60-I; C, 2; D, I5; C. fe, cf2-I; C. cu IVSA, LMG76I0; B, LMGII033. 


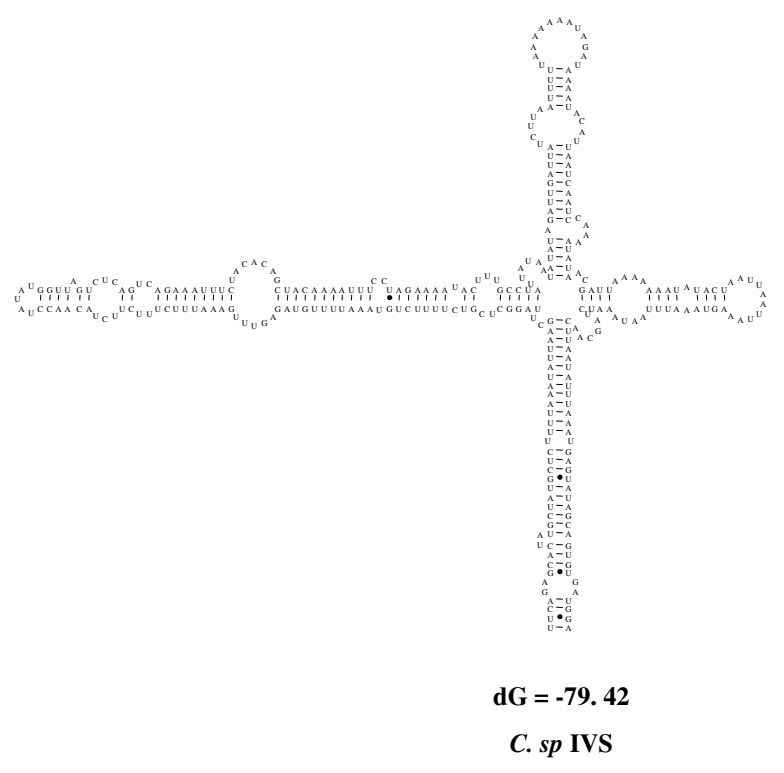

\section{Figure 5}

Secondary structures of IVSs in the helix 25 region from C. sputorum biovar sputorum LMG7975. Some details of the IVSs were shown in Table I. Secondary structure predictions were obtained using the mfold server available at bioinfo's home page.

In relation to the IVSs in the helix 45 from the C. jejuni and C. coli isolates, a total of 149 isolates $(\mathrm{n}=32$ C. jejuni; $\mathrm{n}=117$ C. coli) have already been examined [17-20]. In the two major and typical C. jejuni and C. coli species of Campylobacter, IVSs occur in helix 45 at high percent degree $(59 \%$ for $C$. jejuni $\mathrm{n}=32 ; 84 \%$ for C. coli $\mathrm{n}=117)$ $[2,6,19,20]$. In the present study, the occurrence of IVSs with the two typical Campylobacter species, were shown in helix 45 region at a high similar percentage ( $54 \%$ for $C$. jejeuni $\mathrm{n}=56 ; 45 \%$ for $C$. coli $\mathrm{n}=11$ ), as shown in Table 2. In addition, IVSs have already been shown to occur in the helix 45 region for only a few other Campylobacter species, than the typical C. jejuni and C. coli $(\mathrm{n}=2$ C. upsaliensis; $\mathrm{n}=2$ C. fetus $; \mathrm{n}=1$ C. concisus; $\mathrm{n}=1$ C. hyointestinalis; $\mathrm{n}=1$ C. mucosalis; $\mathrm{n}=3$ C. sputorum), three IVSs being identified to occur in C. fetus and in C. upsaliensis [17]. At present, we identified the majority $(62 / 83)$ of isolates from the three Campylobacter species of C. fetus, C. upsaliensis and C. curvus to carry IVSs in helix 45 within $23 \mathrm{~S}$ rRNA genes. However, in a total of 54 isolates of the three Campylobacter species of C. hyointestinalis $(\mathrm{n}=30)$, C. sputorum $(\mathrm{n}=14)$ and $C$. concisus $(\mathrm{n}=10)$, no IVSs were identified in helix 45 region, as shown in Table 2. These are also scientifically significant observations. Thus, in conclusion, no IVSs were identified in 105 isolates of three Campylobacter species (C. hyointestinalis, C. concisus and C. lari) both in the 25 and 45 helix regions within the $23 \mathrm{~S}$ rRNA genes.

Overall, in the present study, two different kinds of the 23S rRNA genes with and without the IVSs occurred in the seven Campylobacter isolates $(\mathrm{n}=3$ C. sputorum biovar fecalis; $\mathrm{n}=2$ C. jejuni; $\mathrm{n}=2$ C. upsaliensis) (data not shown).

In addition, in the present study, electrophoretic profiles of the purified RNA from Campylobacter organisms were examined. In the purified RNA fractions of some isolates from C. sputorum and C. curvus, slightly shorter 16S rRNA were identified to occur (lanes 2, 3 and 4 in Fig. 7A and lane 6 in Fig. 7B), as described above. These may be partially due to occurrence of IVS within the 16S rRNA genes from these isolates and fragmentation of the primary $16 \mathrm{~S}$ rRNA transcripts among these isolates. However, we have not clarified the nature of the 16S rRNA genes from these isolates, yet. Therefore, sequencing and alignment analyses of the complete 16S rRNA genes from these isolates are needed to identify the nature of the rRNA from these two Campylobacter species. Research to examine this is now in progress.

\section{Conclusions}

Consequently, in 267 isolates of 269 Campylobacter isolates of the nine species $(\mathrm{n}=56$ C. jejuni; $\mathrm{n}=11$ C. coli; $\mathrm{n}$ $=33$ C. fetus: $\mathrm{n}=65$ C. lari; $\mathrm{n}=43$ C. upsaliensis; $\mathrm{n}=30$ C. hyointestinalis; $\mathrm{n}=14$ C. sputorum; $\mathrm{n}=10$ C. concisus; $\mathrm{n}=7$ C. curvus) examined, the absence of IVSs was identified in helix 25 region within $23 \mathrm{~S}$ rRNA genes. Thus, IVS is extremely rare in the helix 25 region within the 23S rRNA genes from the Campylobacter organisms.

The occurrence of IVSs with the two typical Campylobacter species, were shown in helix 45 region at a high percentage ( $54 \%$ for $C$. jejeuni $\mathrm{n}=56 ; 45 \%$ for $C$. coli $\mathrm{n}=11$ ). We also identified the majority $(62 / 83)$ of isolates from the three Campylobacter species of C. fetus, C. upsaliensis and C. curvus to carry IVSs in helix 45. However, in a total of 54 isolates of the three species of $C$. hyointestinalis $(\mathrm{n}=30), C$. sputorum $(\mathrm{n}=14)$ and C. concisus $(\mathrm{n}=10)$, no IVSs were identified in the region.

Thus, in conclusion, no IVSs were identified in 105 isolates of three Campylobacter species (C. hyointestinalis, C. concisus and C. lari) both in the 25 and 45 helix regions. In addition, intact $23 \mathrm{~S}$ rRNAs were identified in the purified RNA fractions in Campylobacter isolates containing no IVSs, and no 23S rRNA and fragmented other smaller RNA fragments were evident in the isolates containing IVSs.

\section{Methods}

Campylobacter isolates and genomic DNA preparation

A total of 204 Campylobacter isolates [C. jejuni $(\mathrm{n}=56) ; C$. coli $(\mathrm{n}=11) ;$. fetus $(\mathrm{n}=33)$ C. upsaliensis $(\mathrm{n}=43) ; C$. 


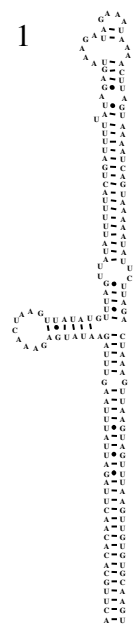

$d G=-61.40$

C. je IVSA
2

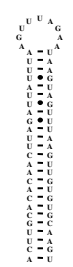

$\mathbf{d G}=\mathbf{- 3 2 . 1 0}$

C. je IVSD
3

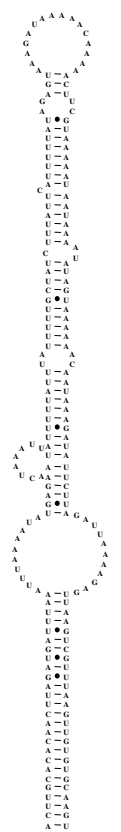

$d G=-61.70$

C. up IVSA
4
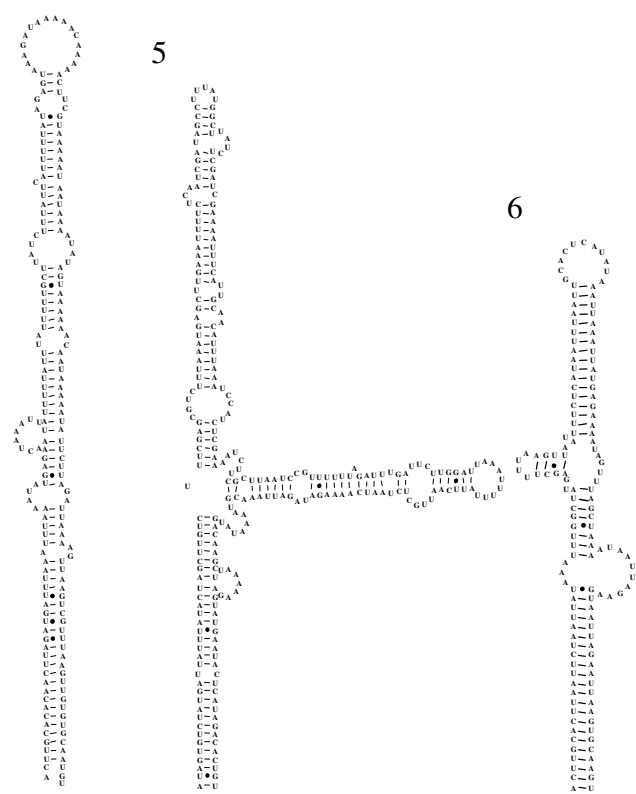

$\mathrm{dG}=-\mathbf{6 1 . 4 0}$

C. fe IVS

Figure 6

Secondary structures of IVSs in the helix $\mathbf{4 5}$ region from Campylobacter isolates. For other details, refer to legend to Figure 4.
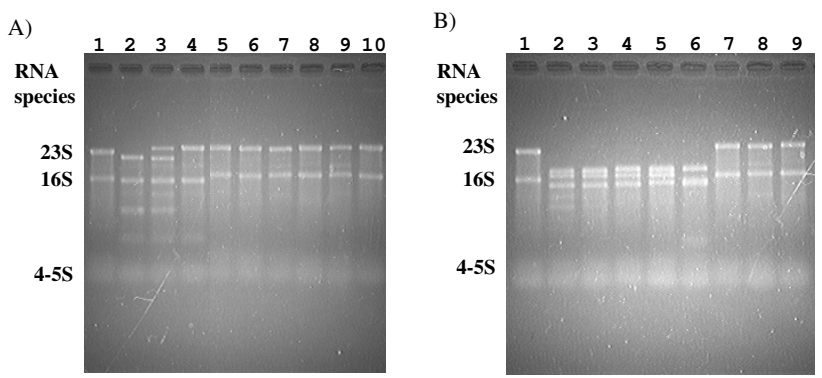

\section{Figure 7}

Electrophoretic profiles of purified RNA from the Campylobacter isolates containing IVSs. In the helix 25 (A) and 45 (B) regions within 23S rRNA genes. Purified RNA from $E$. coli $\mathrm{DH} 5 \alpha$ was employed as a reference marker (lane I). (A) Lane 2, C. sputorum bv. sputorum LMG7975; lane 3, bv. fecalis LMG 853I; lane 4, bv. fecalis LMG II76I; lane 5, C. coli NCTCI I 366; lane 6, C. upsaliensis I2-I; lane 7, C. fetus 84I4c; lane 8, C. hyointestinalis ATCC352 I7; lane 9, C. concisus LMG 7789; lane 10, C. curvus LMGI3935. (B) Lane 2, C. jejuni 8I- I76; lane 3, C. coli 165; lane 4, C. upsaliensis LMG8850; lane 5, C. fetus ATCC27374; lane 6, C. curvus LMG 7609; lane 7, C. upsaliensis I2-I; lane 8, C. fetus 84I4c; lane 9. C. hyointestinalis ATCC35217. hyointestinalis $(\mathrm{n}=30) ; C$. sputorum biovar sputorum $(\mathrm{n}=$ $4)$; biovar fecalis $(n=5)$; biovar paraureolyticus $(n=5)$; C. concisus $(\mathrm{n}=10) ; C$. curvus $(\mathrm{n}=7)$ ] were used in the present study (Table 2). Genomic DNA was prepared from Campylobacter cells by cethyltrimethyl ammonium bromide and proteinase K treatments, phenol-chloroform extraction and ethanol precipitation [23].

\section{PCR amplification, cloning and sequencing}

We have already designed two PCR primer pairs, f-/r$\mathrm{Cl} 23 \mathrm{~h} 25$, constructed to amplify helix 25 region and $\mathrm{f}-\mathrm{r}-$ $\mathrm{Cl23h} 45$, helix 45 region within the 23S rRNA gene sequences, based on the 23S rRNA gene sequence information from 12 UPTC isolates (DDBJ/EMBL/GenBank accsssion numbers, $\mathrm{AB} 287301-\mathrm{AB} 287312), C$. jejuni TGH9011 (Z29326) and C. coli VC167 (U09611) (Fig. 8) [22].

PCR products, separated by $1 \%(\mathrm{w} / \mathrm{v})$ agarose gel electrophoresis in $0.5 \times$ TBE, were purified with QIAquick PCR Purification Kit (QIAGEN, Tokyo, Japan). The purified amplicons were subjected to cycle sequencing with BigDye Terminator (Applied Biosystems, Tokyo, Japan) and with the PCR primers (f-/r-Cl23h25 or f-/r-Cl23h45) and the reaction products were separated and detected 
Table 2: Summary of identification of IVSs within 23 S rRNA genes from Campylobacter organisms analyzed in the presen study

\begin{tabular}{lcc}
\hline Campylobacter species & IVS in helix 25 & IVS in helix 45 \\
\hline C. jejuni $(\mathrm{n}=56)$ & 0 & 30 \\
C. coli $(\mathrm{n}=\mathrm{II})$ & 0 & 5 \\
C. fetus $(\mathrm{n}=33)$ & 0 & 25 \\
C. upsaliensis $(\mathrm{n}=43)$ & 0 & 30 \\
C. hyointestinalis $(\mathrm{n}=30)$ & 0 & 0 \\
C. sputorum biovar sputorum $(\mathrm{n}=4)$ & 1 & 0 \\
C. sputorum biovar fecalis $(\mathrm{n}=5)$ & 3 & 0 \\
C. sputorum biovar paraureolyticus $(\mathrm{n}=5)$ & 0 & 0 \\
C. concisus $(\mathrm{n}=10)$ & 0 & 0 \\
C. curvus $(\mathrm{n}=7)$ & 0 & 0 \\
C. lari $(\mathrm{n}=65)$ & 0 & 96 \\
\hline Total $(\mathrm{n}=269)$ & 0 & 9 \\
\hline
\end{tabular}

\section{A) $23 \mathrm{~S}$ rRNA gene}

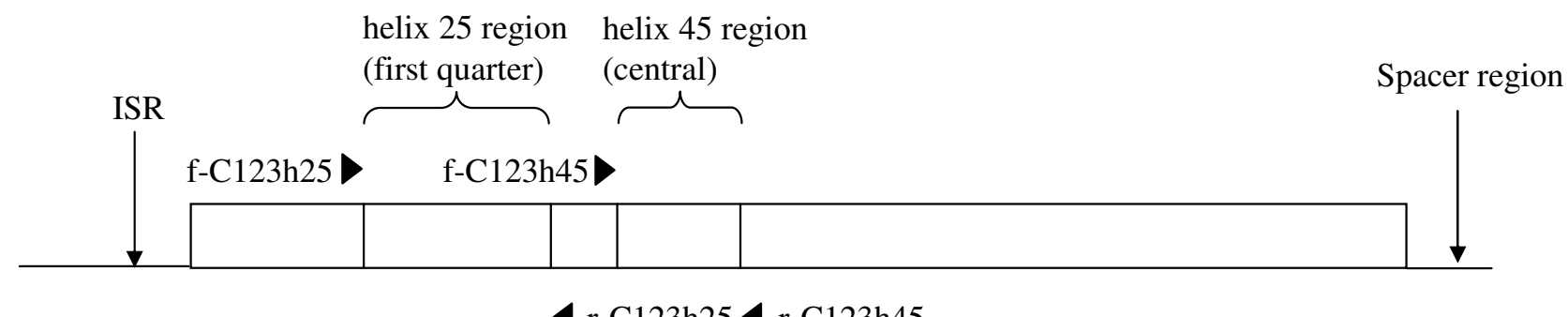

B) Oligonucleotide primers used in the present study

\begin{tabular}{lll}
\hline Primer & Origin & Sequence (5'-3') \\
\hline f- Cl23h25 & present study & AGTACCGTGAGGGAAAGG \\
r- $\mathrm{Cl} 23 \mathrm{~h} 25$ & present study & GGTACATTGGTGTATGCCC \\
f- $\mathrm{Cl} 23 \mathrm{~h} 45$ & present study & AGGTTGGCTTAGAAGCAGCC \\
r- $\mathrm{Cl} 23 \mathrm{~h} 45$ & present study & CTTAGGACCCGACTAACCC \\
\hline
\end{tabular}

Figure 8

A schematic representation of a 23S rRNA gene including two helix regions. Arrows indicate primer site for PCR amplification (A). Sequences of oligonucleotide primers used in the present study (B). ISR, internal spacer region. 
with an ABI PRIM ${ }^{\mathrm{TM}} 3100$ Genetic analyzer (Applied Biosystems). When any multiple IVSs were suggested to occur from the cycle sequencing profiles, the purified amplicons were then cloned into pGEM-T vector (Promega Corp. Tokyo, Japan) and the ligated recombinant DNA was transformed into competent Escherichia coli JM109 cells, [23]. Following the nucleotide sequencing reaction with M13, sequencing of the amplicons was performed with Hitachi SQ5500EL DNA autosequencer (Hitachi Electronics Engineering Co., Tokyo, Japan).

\section{Nucleotide sequence analysis}

Nucleotide sequence analysis was carried out by using the GENETYX-Windows computer software (version 9; GENETYX Co., Tokyo, Japan). Nucleotide sequences of the helix 25 and 45 regions within the 23S rRNA gene sequences from the isolates of campylobacters were compared to each other and with the accessible sequence data from other campylobacters using CLUSTAL W software, respectively (1.7 program) [24], which was incorporated in the DDBJ/EMBL/GenBank databases. The sequence data of the IVSs determined in the present study are accessible in the DDBJ/EMBL/GenBank under accession numbers shown in Table 1.

\section{Secondary structure predictions}

Secondary structure predictions of the IVSs in the helix 25 and 45 within $23 \mathrm{~S}$ rRNA genes from Campylobacter isolates were obtained by using the mfold server available at bioinfo's home page http://www.bioinfo.rpi.edu/applica tions/mfold/rna/forml.cgi.

Total cellular RNA extraction and RNA gel electrophoresis Total cellular RNA was extracted and purified from Campylobacter cells by using RNAprotect Bacteria Reagent and RNeasy Mini Kit (QIAGEN). RNAs were analyzed by denaturing $1 \%(\mathrm{w} / \mathrm{v})$ agarose gel electrophoresis in $1 \%$ (w/v) MOPS (3-morpholinopropanesulfonic acid) containing $2 \%(\mathrm{w} / \mathrm{v})$ formaldehyde after heat denaturation of the total RNA at $65^{\circ} \mathrm{C}$ for $15 \mathrm{~min}$. RNAs were visualized by ethidium bromide staining.

\section{List of abbreviations used}

C: Campylobacter; IVS: intervening sequence; rRNA: ribosomal RNA; E. coli: Escherichia coli.

\section{Authors' contributions}

MM participated in design of the study, collected strains, drafted the manuscript and review of the manuscript. AT, and YK were involved with cloning, sequencing and analysis of the rRNA gene sequences from Campylobacter strains. NM also collected strains. JEM and BCM participated in its design and coordination, and review of the manuscript. All authors have read and approved the final version of this paper.

\section{Acknowledgements}

This research was partially supported by The Promotion and Mutual Aid Corporation for Private Schools of Japan, Grant-in-Aid for Matching Fund Subsidy for Private Universities and by a Grant-in-Aid for Scientific Research (C) (no. 20580346) from the Ministry of Education, Culture, Sports, Science and Technology of Japan (to MM). This study was also partially supported by a project grant (Start Up Support for the Matching Fund Subsidy for Private Universities, 2007-2008) awarded by the Azabu University Research Services Division. MM and JEM were funded through a Great Britain Sasakawa Foundation (Butterfield) Award to examine the clinical significance of Campylobacter infection in the UK and Japan.

\section{References}

I. Lawson AJ, Logan JM, O'Neill GL, Desai M, Stanley J: Large-scale survey of Campylobacter species in human gastroenteritis by PCR and PCR-enzyme-linked immunosorbent assay. J Clin Microbiol 1999, 37:3860-3864.

2. Moore JE, Corcoran D, Dooley JSG, Fanning S, Lucey B, Matsuda M, McDowell DA, Megraud F, Millar BC, O'Mahony R, O'Riordan L, O'Rourke M, Rao RJ, Rooney PJ, Sails A, Whyte P: Campylobacter. Vet Res 36:35I-382.

3. Logan JM, Edwards KJ, Saunders NA, Stanley J: Rapid identification of Campylobacter spp. by melting peak analysis of bioprobes in realtime PCR. J Clin Microbiol 200I, 39:2227-2232.

4. On SL: Identification methods for campylobacters, helicobacters and related organisms. Clin Microbiol Rev 1996, 9:405-422.

5. Yamazaki-Matsune W, Taguchi M, Seto K, Kawahara R, Kawatsu K, Kumeda Y, Kitazato M, Nukina M, Misawa N, Tsukamoto T: Development of a multiplex PCR assay for identification of Campylobacter coli, Campylobacter fetus, Campylobacter hyointestinalis subsp. hyointestinalis, Campylobacter jejuni, Campylobacter lari and Campylobacter upsaliensis. J Med Microbiol 2007, 56: | 467- 1473.

6. Debruyne L, On SL, De BrandtE, Vandamme P: Novel Campylobacter lari-like bacteria from humans and molluscs: description of Campylobacter peloridis sp. nov., Campylobacter lari subsp. concheus subsp. nov. and Campylobacter lari subsp. lari subsp. nov. Int J Syst Evol Microbiol 2009, 59: | | $26-1$ | 32.

7. Aritomi T, Sekizuka T, Imamaki R, Murayama O, Millar BC, Moore JE, Matsuda M: First restriction and genetic mapping of the genomic DNA of urease-positive thermophilic campylobacters (UPTC), and small restriction fragment sequencing. $\mathrm{Br}$ J Biomed Sci 2006, 63:63-67.

8. Fouts DE, Mongodin EF, Mandrell RE, Miller WG, Rasko DA, Ravel J, Brinkac LM, DeBoy RT, Parker CT, Daugherty SC, Dodson RJ, Durkin AS, Madupu R, Sullivan SA, Shetty JU, Ayodeji MA, Shvartsbeyn A, Schatz MC, Badger JH, Fraser CM, Nelson KE: Major structural differences and novel potential virulence mechanisms from the genomes of multiple campylobacter species. PLoS Biol 2005, 3:72-85.

9. Miller WG, Wang G, Binnewies TT, Parker CT: The complete genome sequence and analysis of the human pathogen Campylobacter lari. Foodborne Pathog Dis 2008, 5:37I-386.

10. Burgin $A B$, Parodos $K$, Lane DJ, Pace NR: The excision of intervening sequences from Salmonella 235 ribosomal RNA. Cell 1990 , 60:405-4I4

II. Conlan LH, Stanger MJ, Ichiyanagi K, Belfort M: Localization, mobility and fidelity of retrotransposed group II introns in rRNA genes. Nucleic Acid Res 2005, 33:5262-5270.

12. Kordes E, Jock S, Fritsch J, Bosch F, Klug G: Cloning of a gene involved in rRNA precursor processing and 235 rRNA cleavage in Rhodobacter capsulatus. J Bacteriol 1994, I76: I | | I- I 27.

13. Everett KDE, Kahane S, Bush RM, Friedman MG: An unspliced group I intron in 23S rRNA links Chlamydiales chloroplasts, and mitochondria. J Bacteriol 1999, I 8 I:4734-4740.

14. Hsu D, Shih LM, Zee YC: Degradation of rRNA in Salmonella strains: a novel mechanism to regulate the concentrations of rRNA and ribosomes. J Bacteriol 1994, I 76:476I-4765.

15. Pronk LM, Sanderson KE: Intervening sequences in rrl genes and fragmentation of 23S rRNA in genera of the family Enterobacteriaceae. J Bacteriol 200 I, 183:5782-5787. 
16. Selenska-Pobell S, Doring $\mathrm{H}$ : Sequences around the fragmentation sites of the large subunit ribosomal RNA in the family Rhizobiaceae. Antonie Leeuwenhoek 1998, 73:55-67.

17. Van Camp G, Van De Peer Y, Nicolai S, Neefs J-M, Vandamme P, De Wachter R: Structure of I6S and 23S ribosomal RNA genes in Campylobacter species: Phylogenetic analysis of the genus Campylobacter and presence of internal transcribed spacers. Syst Appl Microbiol 1993, 16:361-368.

18. Konkel ME, Marconi RT, Mead DJ, Cieplak W Jr: Identification and characterization of an intervening sequence within the $23 \mathrm{~S}$ ribosomal RNA genes of Campylobacter jejuni. Mol Microbiol 1994, 14:235-241.

19. Trust TJ, Logan SM, Gustafson CE, Romaniuk PJ, Kim NW, Chan VL, Ragan MA, Guerry P, Gutell RR: Phylogenetic and molecular characterization of a 23S rRNA gene positions the genus Campylobacter in the epsilon subdivision of the Proteobacteria and shows that the presence of transcribed spacers is common in Campylobacter spp. J Bacteriol 1994, I 76:4597-4609.

20. Chan K, Miller WG, Mandrell RE, Kathariou S: The absence of intervening sequences in 23S rRNA genes of Campylobacter coli isolates from turkeys is a unique attribute of a cluster of related strains which also lack resistance to erythromycin. Appl Environ Microbiol 2007, 73: | 208-12/4.

21. Matsuda M, Moore JE: Urease-positive thermophilic Campylobacter species. Appl Environ Microbiol 2004, 70:44I5-44I8.

22. Tazumi A, Kakinuma Y, Takaku C, Sekizuka T, Moore JE, Millar BC, Taneike I, Matsuda M: Demostration of the absence of intervening sequences (IVSs) within 23S rRNA genes from Campylobacter lari. J Basic Microbiol 2009, 49:386-394.

23. Sambrook J, Russell DW: Molecular cloning. a laboratory manual 3rd edition. Cold Spring Harbor, New York, USA: Cold Spring Harbor Laboratory Press; $200 \mathrm{I}$.

24. Thompson JD, Higgins DG, Gibson TJ: CLUSTAL W: improving the sensitivity of progressive multiple sequence alignment through sequence weighting, position-specific gap penalties and weight matrix choice. Nucleic Acids Res 1994, 22:4673-4680.

Publish with Bio Med Central and every scientist can read your work free of charge

"BioMed Central will be the most significant development for disseminating the results of biomedical research in our lifetime. "

Sir Paul Nurse, Cancer Research UK

Your research papers will be:

- available free of charge to the entire biomedical community

- peer reviewed and published immediately upon acceptance

- cited in PubMed and archived on PubMed Central

- yours - you keep the copyright
BioMedcentral 